\title{
Using the Theory of Planned Behavior to Understand Traffic Violation Behaviors in E-Bike Couriers in China
}

\author{
Qian Cheng ${ }^{1},{ }^{1}$ Wei Deng, ${ }^{2}$ and Qizhou $\mathrm{Hu}^{3}$ \\ ${ }^{1}$ School of Transportation and Management, Nanjing Institute of Railway Technology, Nanjing 210031, China \\ ${ }^{2}$ School of Transportation, Southeast University, Si Pai Lou No. 2, Nanjing 210096, China \\ ${ }^{3}$ School of Automation, Nanjing University of Science and Technology, Nanjing 210094, China \\ Correspondence should be addressed to Qian Cheng; 13851522967@139.com
}

Received 24 April 2021; Accepted 21 October 2021; Published 8 November 2021

Academic Editor: Dongjoo Park

Copyright ( 92021 Qian Cheng et al. This is an open access article distributed under the Creative Commons Attribution License, which permits unrestricted use, distribution, and reproduction in any medium, provided the original work is properly cited.

This paper identifies salient beliefs that influence e-bike couriers' traffic violation behavior based on the theory of planned behavior (TPB). Two surveys were conducted in Nanjing, China, in 2018. The first survey extracted the key psychological beliefs, which were used to design a questionnaire. The second survey assessed TPB components and reported e-bike couriers' traffic violation behavior. A structural equation model was adopted to analyze the data. The results revealed that attitudes, descriptive norms, and perceived behavioral control explained $55.7 \%$ of the variance in intention to perform traffic violation behavior, and intentions together with perceived behavior control accounted for $28.5 \%$ of the variance in self-reported violation riding behavior. All of the belief composites had strong direct impacts on their respective TPB constructs. Salient beliefs were applied to develop effective intervention strategies. Age, education level, whether one possessed a driver's license, and past traffic violation behaviors had significant effects on belief composites and behavior. The quantitative analysis results obtained in the study can provide theoretical support for designing more effective interventions for reducing the traffic violation rate of e-bike couriers.

\section{Introduction}

With the rapid development of e-commerce and the logistics industry, demand in the logistics market is dramatically increasing. Delivery with an e-bike is a useful means of solving the problem of logistics and distribution within the last mile. However, with the increase in e-bike couriers, traffic accidents involving such couriers are exhibiting an upward trend in many cities in China. For example, in Shanghai, 117 road accidents involving e-bike couriers killed 9 people and injured 134 others in 2017 [1]. In Suzhou, one delivery boy has had 12 traffic accidents in one month in 2018 [2]. In Nanjing, 40\% of traffic accidents involved e-bike couriers in the second quarter of 2018 [3]. According to Nanjing Annual Traffic Safety Report [4], these accidents primarily resulted from courier violation behaviors, including running red lights, speeding, and the use of motorized-traffic lanes. A large number of empirical studies have confirmed that traffic psychology factors are effective predictors of violation behaviors, and in-depth study of the cause-and-effect relationship between psychological factors and violation behaviors can provide a theoretical foundation for the design of interventions. [5-8].

The theory of planned behavior (TPB) is the most widely known theory regarding attitude-behavior in social psychology and has been found to be well supported by empirical evidence $[9,10]$. According to the TPB, behavioral intentions and perceived behavioral control are a contiguous behavioral domain. Perceived behavioral control can directly affect behavior. It can also indirectly affect behavioral intentions. The TPB also contends that the intention to perform a specific behavior is directly influenced by attitude, injunctive norms, and descriptive norms $[11,12]$.

Fishbein and Ajzen [13] argued that attitude toward the behavior is considered to be based on behavioral beliefs, which are a combination of behavior consequences and evaluations of the consequence. Injunctive normative beliefs determine injunctive norms, which are views regarding the 
behavior of other important individuals or groups and the strength of the motivation of an individual to comply with these groups. Similarly, descriptive normative beliefs serve as the foundation for descriptive norms, which are based on identifying with the behavior of other important referents. Finally, control beliefs are determinants of perceived control, which are perceptions regarding the presence of factors that facilitate or impede the adoption of a given behavior.

The TPB has been widely applied to study traffic violation behaviors. Chorlton et al. [6] constructed a TPB model for predicting motorcyclists' intention to speed. Zhou et al. [14] applied the TPB to analyze why individuals use mobile phones while driving. Barton et al. [15] employed the TPB to examine intentions to cross under varying types of distraction. Jiang et al. [16] examined the efficacy of the TPB model in explaining and predicting fatigued driving behavior. In traffic safety studies, basic TPB constructs, including attitude, subjective norm, and perceived control, could usually explain $0.10-0.55$ of the variance of intention. To increase the interpretative ability of the TPB model, several scholars included extended constructs in the modal. Moan and Rise [17] applied the TPB extended with moral norms and descriptive norms to predict intentions not to drink and drive. Zhou et al. [18] applied the TPB with new added factors, including descriptive norms, perceived risk, and conformity tendency, to study pedestrians' illegal crossing behavior.

Previous studies have also shown that demographic variables can potentially influence the traffic violation behavior. Yang et al. [19] demonstrated that older e-bike riders and individuals with college degrees have lower intention to run red lights, while married individuals have higher intention. Jiang et al. [20] discovered that the gender variable is significant with respect to pedestrians' red-light running behaviors.

Ajzen [21] proposed that beliefs are the ultimate psychological determinants and should be targeted by interventions aimed to alter behavior. However, few studies have applied the TPB to accessed beliefs in an effort to change traffic violation behavior by effective interventions. In addition, few studies have investigated the psychological factors of e-bike couriers' traffic violation behavior. To fill these gaps, in this paper, we predict and explain e-bike couriers' self-reported traffic violation behavior with the standard TPB. We identify the most important beliefs regarding traffic violation behavior for e-bike couriers and seek developing an intervention strategy for altering the violation behavior of such couriers based on these beliefs. We investigate whether demographic variables directly affect traffic violation behavior and examine the relationship between personal characteristics and various constructs of beliefs. Accordingly, the following hypotheses were developed:

(1) The constructs of the TPB measured in advance predict the self-reported traffic violation behavior over the following week

(2) The relations between salient beliefs regarding traffic violation behavior and the constructs of the TPB are significant
(3) E-bike couriers' demographic variables directly or indirectly affected traffic violation behavior

The remainder of this paper is structured as follows. The design of the questionnaires is presented in the "Survey Method" section. The data analysis is described in the "Results" section. Finally, the "Discussion" section summarizes the significant findings and suggests avenues for future research.

\section{Survey Method}

2.1. Pilot Study. According to the TPB, different target populations have different perceptions of behavior. An arbitrarily or intuitively selected set of belief statements may not represent the readily accessible beliefs of the target population [11]. Therefore, a pilot study with an open-ended questionnaire was conducted to elicit e-bike couriers' key beliefs regarding traffic violation behavior.

The pilot participants were recruited in May 2018 from five logistics companies in Nanjing, China. A total of 100 couriers responded. The couriers were provided with a definition of traffic violation behavior: red-light running, speeding, and using motorized-traffic lanes. They were then asked to write down their thoughts when they performed these types of behavior. Specifically, behavioral beliefs were measured by asking the respondents to list the advantages and disadvantages of performing a traffic violation behavior during their next delivery with an e-bike. Normative referents were assessed by asking the respondents to indicate which persons or group of people would approve or disapprove of performing traffic violation behavior in the next delivery with an e-bike. Control beliefs were evaluated by asking respondents to list factors that could make it easy or difficult for them to perform traffic violation behavior in the next delivery with an e-bike. In order to eliminate the social desirability bias, we assured the pilot participants of anonymity and convinced them that the accuracy of their self-reports can be verified.

To obtain the most accessible beliefs, the questionnaires were analyzed by two researchers independently. First, the two researchers examined the semantic content of the responses in each questionnaire and placed the beliefs into categories with different coding frames [22]. These different coding frames were adopted for the questions regarding advantages and disadvantages, approval and disapproval, and easiness and difficulty. Second, Cohen's kappa was calculated to evaluate the consistency in the classification of the two researchers. Third, the Spearman correlation and the interclass correlation were calculated to verify the consistency in the number of different semantic contents counted by two researchers. The results are shown in Table 1 .

Based on the statistical results presented in Table 1, we used the most frequently cited items to develop the quantitative measures of behavioral, normative, and control beliefs in the standard questionnaire.

2.2. Main Study. The main study was conducted from August to October 2018. The respondents were recruited from the same logistics companies as in the pilot study. 
TABLE 1: Consistency and correlations of beliefs.

\begin{tabular}{|c|c|c|c|c|}
\hline Category & Most frequently cited items & Cohen's kappa & $\rho$ & ICC \\
\hline Advantage & $\begin{array}{l}\text { Save time } \\
\text { More convenient } \\
\text { The more the deliveries, the higher the earnings }\end{array}$ & 0.92 & $0.96^{* * *}$ & $0.99^{* * *}$ \\
\hline Disadvantage & $\begin{array}{c}\text { Traffic accident } \\
\text { Injury severity } \\
\text { Social and public pressure }\end{array}$ & 0.95 & $0.90^{* *}$ & $0.92^{* *}$ \\
\hline Approve & $\begin{array}{c}\text { Workmates } \\
\text { Supervisors } \\
\text { Service subscribers } \\
\end{array}$ & 0.83 & $0.84^{*}$ & $0.89^{*}$ \\
\hline Disapprove & $\begin{array}{c}\text { Friends } \\
\text { Family } \\
\text { Other road users } \\
\end{array}$ & 0.89 & $0.79^{*}$ & $0.81^{*}$ \\
\hline Easy & $\begin{array}{c}\text { Received urgent request from customers } \\
\text { A large number of delivery parcels } \\
\text { Heavy goods vehicles } \\
\text { Familiarity with the local roads }\end{array}$ & 0.86 & $0.91^{* * *}$ & $0.85^{* * *}$ \\
\hline Difficult & $\begin{array}{c}\text { Illegal behavior fine } \\
\text { Traffic police officers on duty }\end{array}$ & 0.91 & $0.87^{* *}$ & $0.91^{* *}$ \\
\hline
\end{tabular}

Note. ${ }^{* * *} P<0.001,{ }^{* *} P<0.01$, and ${ }^{*} P<0.05$; $\rho$ : Spearman correlation coefficient; ICC: interclass correlation coefficient.

There were two questionnaires in the main study. The first questionnaire consisted of three parts. The first part contained questions relating to the respondents' demographic characteristics, including gender, age, and income. The second part was designed to measure the couriers' beliefs, while the third part consisted of questions regarding basic TPB constructs (e.g., attitude, injunctive norms, descriptive norms, perceived behavior control, and behavior intention). To reduce the statistical bias of under- or overreporting, the thematic version of the questionnaire was created. In the questionnaire, the traffic violation behaviors were presented in separate sections, with items assessing a given construct appearing consecutively. The order of the behaviors was counterbalanced. The second questionnaire was developed to collect the respondents' traffic violation behavior over the following week and was administered one week after the first questionnaire was completed. A total of 432 couriers out of 500 respondents completed both questionnaires.

2.2.1. Beliefs. According to an expectancy-value model [13], the attitude is affected by behavior beliefs, and such beliefs could be evaluated by the likelihood and the importance of the behavioral outcome, as in the following equation:

$$
A \propto \sum b_{i} e_{i},
$$

where $A$ is the attitude of the e-bike courier toward an object, $b_{i}$ is the strength of the belief that the object has attribute $i$, and $e_{i}$ is the evaluation of attribute $i .2 b_{i} e_{i}$ is the overall evaluation of beliefs. To maintain consistency, the same expectancy-value model is applied to obtain the score of each construct of the beliefs.

Behavioral beliefs were measured by the likelihood and the importance of the six potential outcomes of e-bike couriers performing traffic violation behavior. The respondents rated the likelihood of the outcome on a 7-point scale from 1 to 7 ranging from "very unlikely" to "very likely" and the importance of the outcome on a 7-point scale from 1 to 7 ranging from "not important at all" to "very important." The six outcomes were as follows: "It would save time," "It would make things more convenient for me," "The more the deliveries, the higher the earnings," "It would cause a traffic accident," "It would result in severe injury for me," and "It would place me under social and public pressure."

Injunctive normative beliefs were measured by asking participants to indicate whether they thought that six specific important referents (i.e., workmates, supervisors, service subscribers, friends, family, and other road users) expected them to perform traffic violation behavior and whether the respondents were motivated to comply with these expectations. All items were rated on a 7-point scale ranging from "definitely not" to "yes, definitely."

Descriptive normative beliefs were measured by asking participants to indicate whether they believed that these six important referents would themselves perform traffic violation behavior and whether they (i.e., the participants) were affected by these important referents. All items were rated on a 7-point scale ranging from "definitely not" to "yes, definitely."

A list of 6 control factors was presented to measure control beliefs. The six factors were "I received an urgent request from a customer," "there was a large number of delivery parcels," "I ride a heavy goods scooter," "I am familiar with the local roads," "I would be fined for violation behavior," and "I saw traffic police on the road." Control beliefs were evaluated with respect to the occurrence likelihood and perceived convenience of these factors. The participants rated likelihood on a 7-point scale from 1 to 7 ranging from "very unlikely" to "very likely" and convenience on a 7-point scale from 1 to 7 ranging from "definitely not" to "yes, definitely."

2.2.2. Measures of the TPB Constructs. Semantic differential scales were applied to evaluate the constructs of the TPB, including attitude, injunctive norms, descriptive norms, 
perceived behavioral control, behavioral intention, and traffic violation behavior.

Attitude was assessed on five semantic differential scales for e-bike couriers' traffic violation behavior [23]. The statement "Next time, during delivery with an e-bike, if I commit traffic violation, it would be..." was completed with 7 -point semantic differential choices scales ranging between bad/good, foolish/wise, useless/useful, negative/positive, and harmful/beneficial. A higher score indicates a more positive attitude toward traffic violation behavior.

Injunctive norms were measured by three items: "People who are important to me expect that I perform traffic violation behavior during delivery with an e-bike in the next delivery," "People who agree with me expect that I perform traffic violation behavior during delivery with an e-bike in the next delivery," and "People who I admire expect that I perform traffic violation behavior during delivery with an e-bike in the next delivery." The items were rated on a 7 point scale from 1 to 7 ranging from "completely disagree" to "completely agree."

Descriptive norms were measured by two items. The first item was "Most people like me will perform traffic violation behavior during delivery with an e-bike in their next delivery." The item was rated on a 7-point scale from 1 to 7 ranging from "completely disagree" to "completely agree," respectively. The second item was "How many people like you will perform traffic violation behavior during delivery with an e-bike in the next delivery?" The items were rated on a 7-point scale from 1 to 7 ranging from "never" to "very common."

Perceived behavioral control included perceived autonomy and perceived capacity. Perceived autonomy was measured with one item: "Performing traffic violation behavior during delivery with an e-bike is completely under my control." The item was rated on a 7-point scale from 1 to 7 ranging from "completely disagree" to "completely agree." Perceived capacity was assessed with two items. The first item was "For me, performing traffic violation behavior during delivery with an e-bike would be...." The item was completed with a 7-point scale from 1 to 7 ranging from "very difficult" to "very easy." The other item was "If I decide to, I can easily perform traffic violation behavior during delivery with an e-bike." The item was rated on a 7-point scale from 1 to 7 ranging from "very unlikely" to "very likely."

Behavioral intention was measured via three items: "In the next delivery, I intend to perform traffic violation behavior during delivery with an e-bike," "How likely is it that you will perform traffic violation behavior during delivery with an e-bike in the next delivery," and "I expect to perform traffic violation behavior during delivery with an e-bike in the next delivery." The items were rated on a 7-point scale from 1 to 7 ranging from "very unlikely" to "very likely."

Traffic violation behavior was measured via two items in the second questionnaire. The first item was "In the previous week, how often did you perform traffic violation behavior during delivery with an e-bike?" The item was rated on a 7point scale from 1 to 7 ranging from "never" to "nearly always." The second item was "In the previous week, you performed traffic violation behavior during delivery with an e-bike." The item was rated on a 7-point scale from 1 to 7 ranging from "true" to "false."

\section{Results}

3.1. Descriptive Statistics. We collected demographic characteristics, including gender, age, education level, monthly income, whether the participant possessed a driver's license, and whether the participant had been involved in traffic violation behavior during the previous three months. Table 2 presents the descriptive statistics on the respondent demographics.

Table 3 presents means and standard deviation for all TPB items. Table 4 presents the Pearson correlations and descriptive statistics for all ten psychological variables of the standard TPB. The participants reported relatively weak intentions to perform traffic violation behavior, a negative attitude, relatively low injunctive norms, relatively high descriptive norms, and relatively high perceived control. The low mean of the intention score indicated that the e-bike couriers had weak intentions to perform traffic violations, whereas the relatively high mean of the descriptive norms reflected that the e-bike couriers tended to follow people who are similar to them with respect to performing traffic violation behavior. Similarly, the relatively high scores for perceived behavioral controls revealed that the e-bike couriers felt it was easy for them to perform traffic violation behavior.

In addition, the correlations between four TPB constructs and behavioral intentions and traffic violation behavior were significant. The constructs correlated more strongly with intentions than with behavior. As expected, the behavioral, injunctive, descriptive, and control beliefs were correlated with their associated psychological constructs. The skewness and kurtosis coefficients of latent variables in Table 4 indicate that the observed index of latent variables approximately satisfies normal distribution.

\subsection{Testing the TPB Model. A structural equation model was} constructed to understand how belief composites that accorded with the expectancy-value model influenced the constructs of the TPB model and to identify the significant predictors of e-bike couriers' traffic violation intentions and behavior.

AMOS 23.0 was applied to calibrate the model using the maximum likelihood method. The result is presented in Table 5. The standardized loading items of the TPB constructs are statistically significant $(P<0.05)$ and greater than 0.7 , which indicates that the observed indicators can reflect latent constructs well. Cronbach's alpha of each latent constructs is greater than 0.7 , indicating that the questionnaire has high reliability. The composite reliability and average variance extracted from the measurement model are the important indices with respect to the quality of the model's measurement equation. The composite reliability of six latent constructs is greater than 0.7 and the AVE score ranges from 0.575 to 0.713 , which is greater than the 
TABLE 2: Demographic profile of respondents.

\begin{tabular}{|c|c|c|}
\hline Demographic variable & $N$ & Percent \\
\hline \multicolumn{3}{|l|}{ Gender } \\
\hline Male & 318 & 73.6 \\
\hline Female & 114 & 26.4 \\
\hline \multicolumn{3}{|l|}{ Age (years) } \\
\hline $18-30$ & 137 & 31.7 \\
\hline $31-45$ & 195 & 45.2 \\
\hline $46+$ & 100 & 23.1 \\
\hline \multicolumn{3}{|l|}{ College diploma } \\
\hline Yes & 163 & 37.7 \\
\hline No & 269 & 62.3 \\
\hline \multicolumn{3}{|l|}{ Monthly income (yuan) } \\
\hline$<5000$ & 273 & 63.2 \\
\hline $5000-10000$ & 144 & 33.4 \\
\hline$>10000$ & 15 & 3.4 \\
\hline \multicolumn{3}{|l|}{ Driver's license } \\
\hline No & 330 & 76.3 \\
\hline Yes & 102 & 23.7 \\
\hline \multicolumn{3}{|c|}{ Traffic violation behavior in the past 3 months } \\
\hline Involved & 375 & 86.8 \\
\hline Not involved & 57 & 13.2 \\
\hline
\end{tabular}

TABLE 3: Mean and standard deviation of the score for each item.

\begin{tabular}{|c|c|c|c|c|}
\hline Constructs & Items & Semantic scales & Mean & SD \\
\hline \multicolumn{5}{|l|}{ Attitude } \\
\hline & att1 & Bad/good & 3.25 & 0.83 \\
\hline & att2 & Foolish/wise & 3.01 & 1.26 \\
\hline & att3 & Useless/useful & 5.13 & 0.66 \\
\hline & att4 & Negative/positive & 3.63 & 1.06 \\
\hline & att5 & Harmful/beneficial & 2.95 & 1.12 \\
\hline \multicolumn{5}{|c|}{ Injunctive norms } \\
\hline & ins1 & Completely disagree/completely agree & 2.37 & 1.62 \\
\hline & ins2 & Completely disagree/completely agree & 3.63 & 1.27 \\
\hline & ins3 & Completely disagree/completely agree & 3.52 & 1.05 \\
\hline \multicolumn{5}{|c|}{ Descriptive norms } \\
\hline & $d n s 1$ & Completely disagree/completely agree & 4.06 & 0.55 \\
\hline & $d n s 2$ & Never/very common & 4.13 & 1.07 \\
\hline \multicolumn{5}{|c|}{ Perceived behavior control } \\
\hline & $p c 1$ & Completely disagree/completely agree & 4.91 & 0.63 \\
\hline & $p c 2$ & Very difficult/very easy & 4.76 & 0.72 \\
\hline & $p c 3$ & Very unlikely/very likely & 5.27 & 0.57 \\
\hline \multicolumn{5}{|l|}{ Intention } \\
\hline & int1 & Very unlikely/very likely & 3.81 & 1.71 \\
\hline & int2 & Very unlikely/very likely & 3.27 & 1.07 \\
\hline & int3 & Very unlikely/very likely & 3.39 & 0.95 \\
\hline \multicolumn{5}{|l|}{ Behavior } \\
\hline & $t v b 1$ & Never/nearly always & 2.97 & 1.77 \\
\hline & $t v b 2$ & True/false & 3.09 & 1.63 \\
\hline
\end{tabular}

threshold value of 0.5 . These outcomes reveal that the intrinsic quality of the measurement model is ideal, the convergence validity of the latent constructs is good, and the measurement error is reasonable [24].

The fitness indices of the structural equation model are presented in Table 6. The indices include the comparative fit index (CFI), the goodness-of-fit index (GFI), the normed fit index (NFI), and root mean square error of approximation (RMSEA). All of the indices satisfy the recommended index requirements [24,25], indicating that the model fitting is good, and the hypothetical model is acceptable.

Figure 1 presents the TPB model used to examine the relations between the belief composites and the constructs, as well as the relations between the constructs and e-bike couriers traffic violation intention and behavior. The scores for these belief composites are calculated according to the expectancy-value model, and the constructs of the TPB model are measured by reflective indicators in the first 
TABLE 4: Correlations among measured variables and descriptive statistics.

\begin{tabular}{|c|c|c|c|c|c|c|c|c|c|c|}
\hline Latent variables & $(1)$ & $(2)$ & (3) & $(4)$ & $(5)$ & $(6)$ & $(7)$ & $(8)$ & $(9)$ & $(10)$ \\
\hline (1) Behavioral beliefs & - & & & & & & & & & \\
\hline (2) Injunctive normative beliefs & $0.38^{*}$ & - & & & & & & & & \\
\hline (3) Descriptive normative beliefs & $0.32^{*}$ & $0.51^{*}$ & - & & & & & & & \\
\hline (4) Control beliefs & $0.41^{*}$ & $0.44^{*}$ & $0.37^{*}$ & - & & & & & & \\
\hline (5) Attitude & $0.51^{* *}$ & $0.31^{*}$ & $0.35^{*}$ & $0.45^{*}$ & - & & & & & \\
\hline (6) Injunctive norms & $0.33^{*}$ & $0.61^{* *}$ & $0.49^{* *}$ & $0.37^{*}$ & $0.43^{* *}$ & - & & & & \\
\hline (7) Descriptive norms & $0.33^{*}$ & $0.47^{* *}$ & $0.55^{* *}$ & $0.27^{*}$ & $0.46^{* *}$ & $0.55^{* *}$ & - & & & \\
\hline (8) Perceived behavior control & $0.36^{*}$ & $0.25^{*}$ & $0.23^{*}$ & $0.55^{* *}$ & $0.39^{* *}$ & $0.33^{* *}$ & $0.41^{* *}$ & - & & \\
\hline (9) Intention & $0.43^{*}$ & $0.57^{*}$ & $0.55^{*}$ & $0.48^{*}$ & $0.63^{* *}$ & $0.51^{* *}$ & $0.57^{* *}$ & $0.61^{* *}$ & - & \\
\hline (10) Behavior & $0.23^{*}$ & $0.23^{*}$ & $0.32^{*}$ & $0.37^{*}$ & $0.36^{* *}$ & $0.29^{* *}$ & $0.39^{* *}$ & $0.55^{* *}$ & $0.52^{* *}$ & - \\
\hline Mean & $197.34^{\mathrm{a}}$ & $128.75^{\mathrm{a}}$ & $147.13^{\mathrm{a}}$ & $169.67^{\mathrm{a}}$ & $2.96^{\mathrm{b}}$ & $3.34^{\mathrm{b}}$ & $3.73^{\mathrm{b}}$ & $3.67^{\mathrm{b}}$ & $2.85^{\mathrm{b}}$ & $2.26^{\mathrm{b}}$ \\
\hline Standard deviation & 11.12 & 9.44 & 9.63 & 12.05 & 1.02 & 1.48 & 1.17 & 1.92 & 1.71 & 1.54 \\
\hline Skewness & 0.79 & 1.06 & 0.53 & -0.89 & 0.57 & 0.49 & 0.31 & 0.39 & 0.46 & 0.51 \\
\hline Kurtosis & -0.97 & -1.83 & -0.85 & -1.11 & -0.57 & 0.19 & 0.21 & -0.71 & -0.86 & 0.97 \\
\hline
\end{tabular}

${ }^{*} P<0.05 ;{ }^{* *} P<0.01$. ${ }^{\text {a Theoretical range }}=6-294 .{ }^{\mathrm{b}}$ Theoretical range $=1-7$.

TABLE 5: Reliability and validity analysis of measured model.

\begin{tabular}{|c|c|c|c|c|c|}
\hline Constructs & Items & Standardized loadings & Cronbach's alpha & Composite reliability & Average variance extracted \\
\hline \multirow{5}{*}{ Attitude } & att1 & $0.801^{* * *}$ & \multirow{5}{*}{0.867} & \multirow{5}{*}{0.905} & \multirow{5}{*}{0.656} \\
\hline & att2 & $0.792^{* * *}$ & & & \\
\hline & att3 & $0.788^{* * *}$ & & & \\
\hline & att4 & $0.821^{* * *}$ & & & \\
\hline & att5 & $0.847^{* * *}$ & & & \\
\hline \multirow{3}{*}{ Injunctive norms } & ins1 & $0.793^{* * *}$ & \multirow{3}{*}{0.785} & \multirow{3}{*}{0.834} & \multirow{3}{*}{0.627} \\
\hline & ins2 & $0.769^{* * *}$ & & & \\
\hline & ins3 & $0.812^{* * *}$ & & & \\
\hline \multirow{2}{*}{ Descriptive norms } & $d n s 1$ & $0.828^{* * *}$ & \multirow{2}{*}{0.832} & \multirow{2}{*}{0.835} & \multirow{2}{*}{0.717} \\
\hline & $d n s 2$ & $0.865^{* * *}$ & & & \\
\hline \multirow{3}{*}{ Perceived behavior control } & $p c 1$ & $0.732^{* * *}$ & \multirow{3}{*}{0.813} & \multirow{3}{*}{0.801} & \multirow{3}{*}{0.575} \\
\hline & $p c 2$ & $0.717^{* * *}$ & & & \\
\hline & $p c 3$ & $0.821^{* * *}$ & & & \\
\hline \multirow{3}{*}{ Intention } & int1 & $0.771^{* * *}$ & \multirow{3}{*}{0.869} & \multirow{3}{*}{0.819} & \multirow{3}{*}{0.602} \\
\hline & int2 & $0.759^{* * *}$ & & & \\
\hline & int3 & $0.797^{* * *}$ & & & \\
\hline \multirow{2}{*}{ Behavior } & $t v b 1$ & $0.856^{* * *}$ & \multirow{2}{*}{0.741} & \multirow{2}{*}{0.832} & \multirow{2}{*}{0.713} \\
\hline & $t v b 2$ & $0.832^{* * *}$ & & & \\
\hline
\end{tabular}

${ }^{* * *} P<0.001$.

TABle 6: Model fit summary.

\begin{tabular}{lcccc}
\hline & CFI & GFI & NFI & RMSEA \\
\hline Recommended values & $>0.9$ & $>0.9$ & $>0.9$ & $<0.08$ \\
Model values & 0.923 & 0.956 & 0.941 & 0.061 \\
\hline
\end{tabular}

questionnaire, while the behaviors are assessed in accordance with survey data from the second questionnaire. The TPB model explained $55.7 \%$ of the variance in the couriers' behavioral intentions and $28.5 \%$ of the variance in their reported traffic violation behavior. Thus, hypothesis 1 was supported. Attitude had a strong direct impact on intention, whereas the effects of perceived behavior control and descriptive norms were moderate. Injunctive norms had no significant direct impact on intention. Intentions and perceived control had a moderate direct impact on behavior. All of the belief composites had strong direct impact on their respective constructs.
3.3. Effects of Beliefs. To test hypothesis 2 and to elicit the key individual beliefs regarding traffic violation behavior, we applied a multiple indicators and multiple causes (MIMIC) model [26-28] to investigate whether the TPB constructs could be predicted by individual beliefs.

Figure 2 presents the MIMIC model used to analyze the relations between the behavioral beliefs and the attitude toward behavior. According to the survey data, the score for each belief that an individual holds is calculated by the products of the belief strength and outcome evaluations. The six behavioral beliefs explained $31.7 \%$ of the variance in the e-bike couriers' attitudes. Three individual beliefs were statistically significant. Among them, "I would save time" and "I would receive higher earnings" were strong predictors of attitude toward violation riding behavior. Thus, hypothesis 2 was supported. This model achieved an excellent fit: $\quad \mathrm{CFI}=0.937 ; \quad \mathrm{GFI}=0.953 ; \quad \mathrm{NFI}=0.949$; RMSEA $=0.057$. 


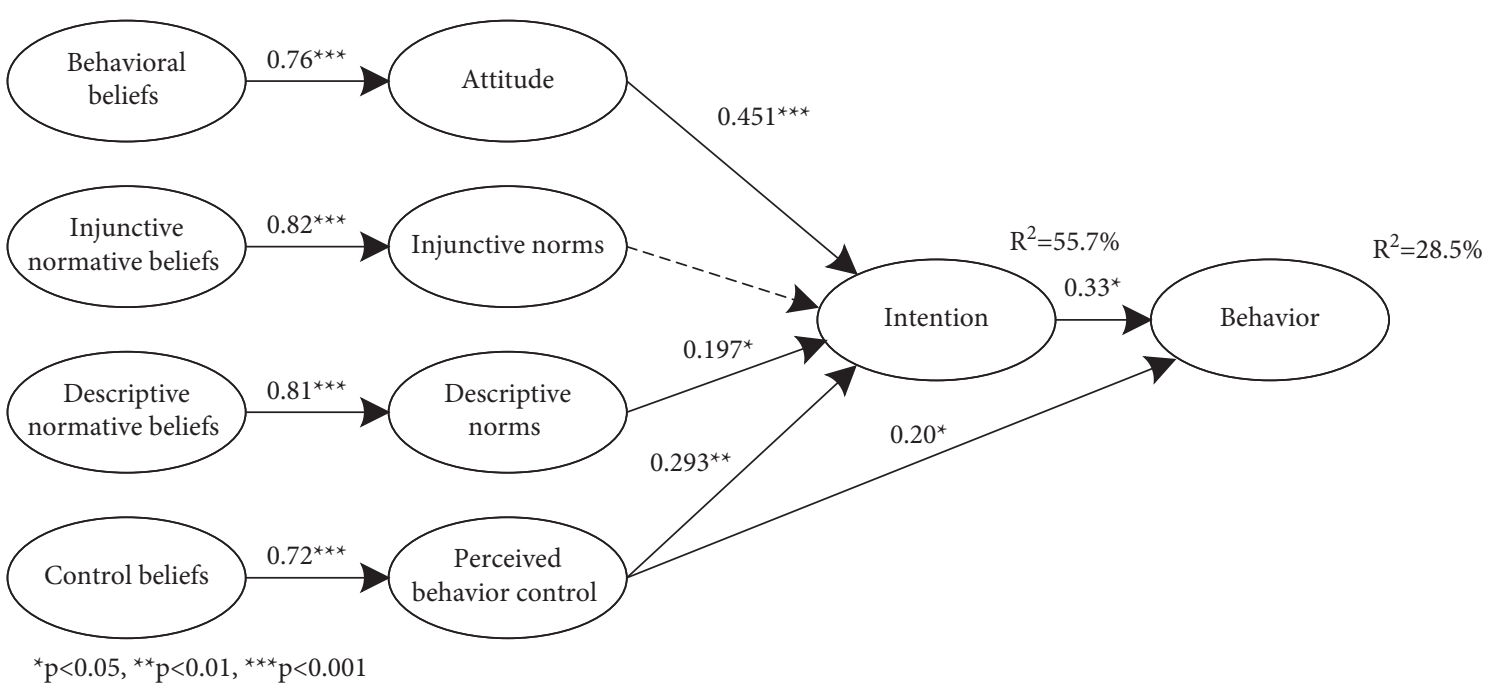

FIGURE 1: TPB model for e-bike couriers' traffic violation behavior.

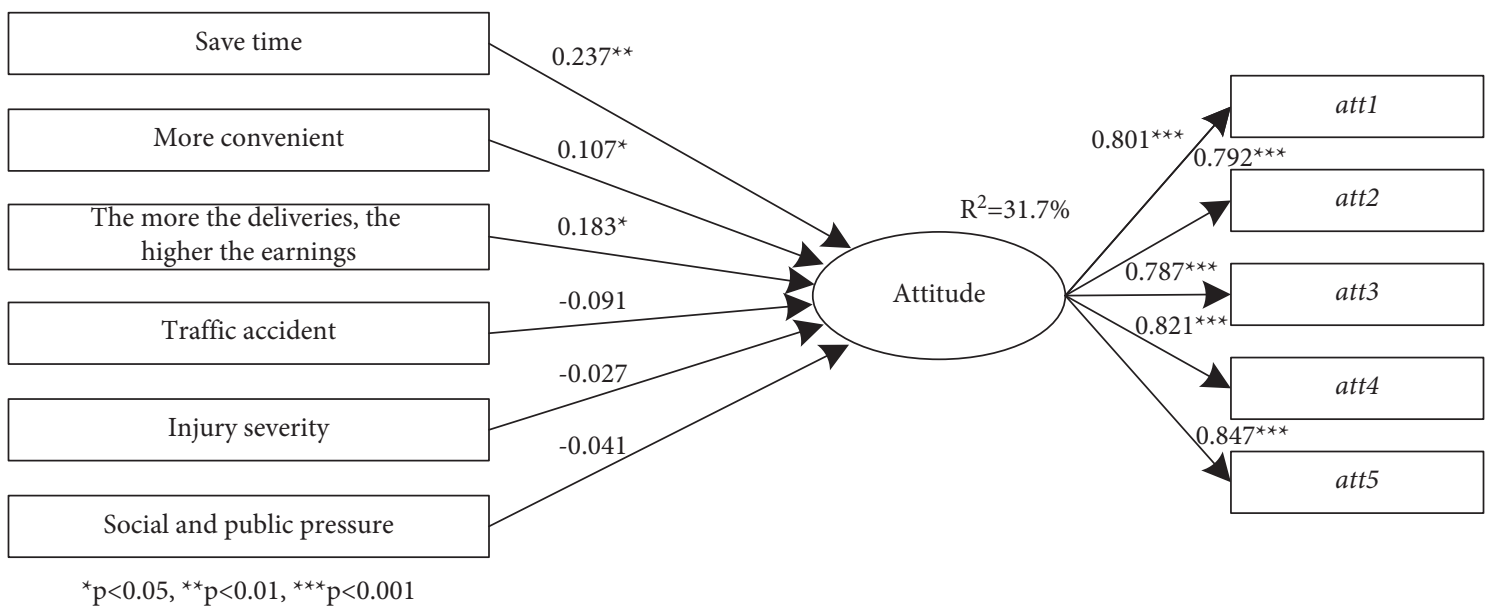

Figure 2: Behavioral beliefs predicting attitude.

We did not analyze the relation of individual injunctive normative beliefs to injunctive norms because injunctive norms had no direct effect on behavioral intentions (Figure 1). As shown in Figure 3, the six descriptive normative beliefs explained $41.3 \%$ of the variance in descriptive norms. The violation riding behavior of important referents, including workmates and other road users, was a strong predictor of descriptive norms. The model provided an excellent fit: $\quad \mathrm{CFI}=0.919 ; \quad \mathrm{GFI}=0.933 ; \quad \mathrm{NFI}=0.928$; RMSEA $=0.061$.

Figure 4 presents a MIMIC model of different control factors predicting perceived behavioral control. The model achieved an excellent fit: $\mathrm{CFI}=0.913 ; \quad \mathrm{GFI}=0.929$; $\mathrm{NFI}=0.935 ; \mathrm{RMSEA}=0.059$. Control factors explained $38.2 \%$ of the variance in perceived behavioral control. There are five control factors with a significant effect. "Received an urgent request from a customer," "Riding a heavy goods scooter," and "Familiarity with the local roads" have positive effects on the couriers' perceived behavioral control, whereas "Will be fined" and "traffic police officers on duty" have negative effects on the couriers' perceived behavioral control.

3.4. Effects of Demographic Variables. To explain the relations between the respondents' demographic variables and their self-reported traffic violation behavior, we applied a MIMIC model to investigate whether these variables would affect the belief composites of the TPB model and whether these variables would affect the e-bike couriers' behavior directly (hypothesis 3 ). Figure 5 presents the model and the results are shown in Table 7 . Here, again, because injunctive norms had no direct effect on behavioral intentions, we did not investigate the effect of individual characteristics on the composite of injunctive beliefs. Gender and monthly income had no effect on the belief composites or self-reported behavior. Having a college degree and possessing a driver's license had negative effects on traffic violation behavior, while e-bike couriers who were younger or who were involved in traffic violation behavior during the previous 3 


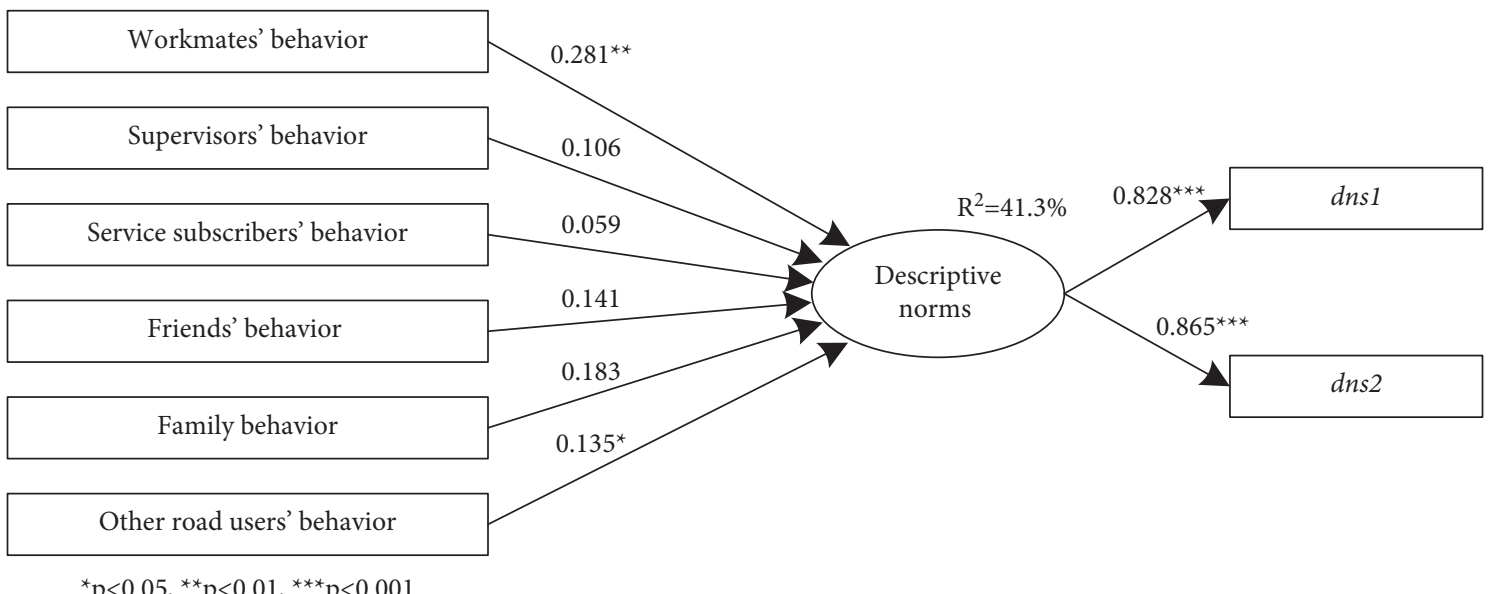

FIgURE 3: Norm referents predicting descriptive norms.

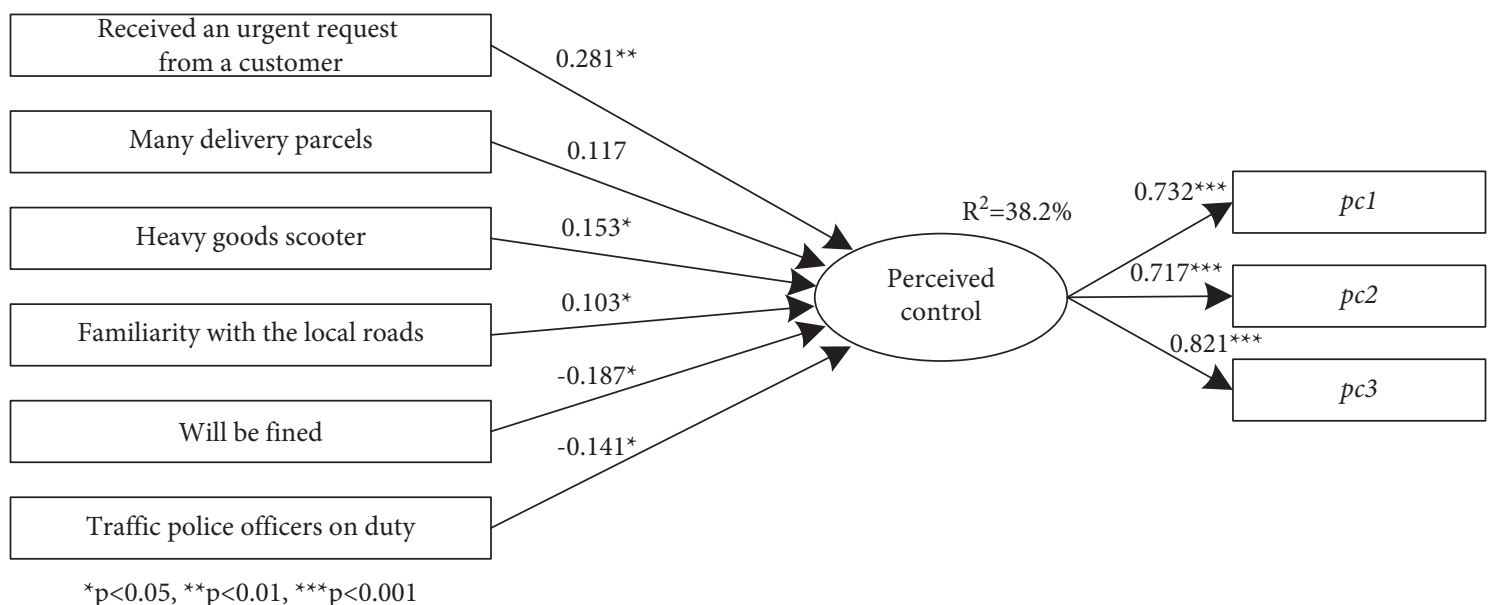

FIGURE 4: Control factors predicting perceived control.

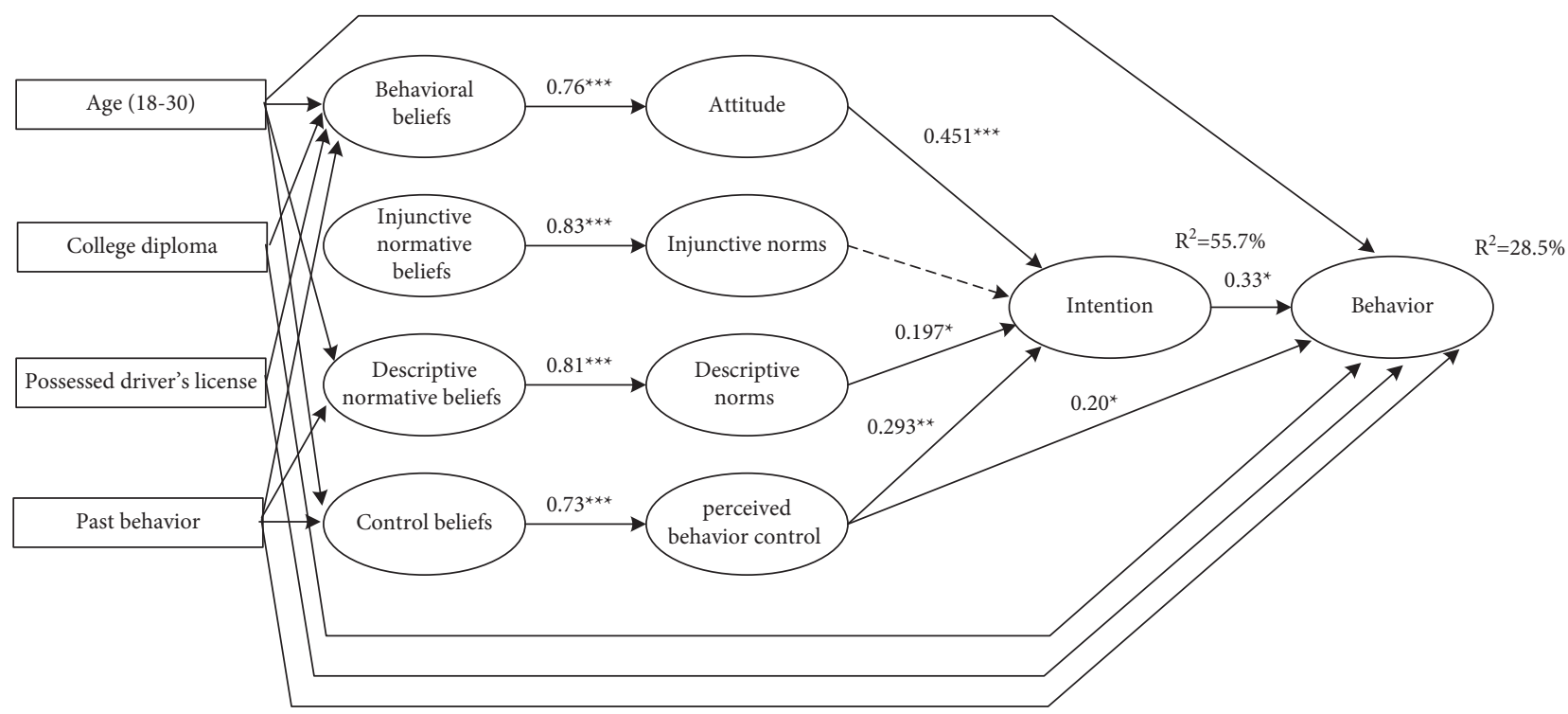

FIGURE 5: TPB model for e-bike couriers' traffic violation behavior and the effects of the demographic variables. 
TABLE 7: Impacts of demographic variables on belief composite and behavior.

\begin{tabular}{|c|c|c|c|c|c|c|c|c|}
\hline \multirow[t]{2}{*}{ Demographic variables } & \multicolumn{2}{|c|}{ Behavioral belief } & \multicolumn{2}{|c|}{$\begin{array}{c}\text { Descriptive } \\
\text { normative belief }\end{array}$} & \multicolumn{2}{|c|}{ Control belief } & \multicolumn{2}{|c|}{ Behavior } \\
\hline & $\beta$ & $P$ value & $\beta$ & $P$ value & $\beta$ & $P$ value & $\beta$ & $P$ value \\
\hline Male & 0.40 & 0.309 & 0.21 & 0.517 & 0.55 & 0.735 & 0.22 & 0.051 \\
\hline Age (18-30) & $0.31^{*}$ & 0.039 & $0.34^{*}$ & 0.042 & $0.27^{*}$ & 0.019 & $0.13^{*}$ & 0.035 \\
\hline Age $(46+)$ & -0.04 & 0.054 & -0.11 & 0.111 & -0.09 & 0.105 & --0.07 & 0.071 \\
\hline College diploma & $-0.09^{*}$ & 0.027 & -0.13 & 0.105 & -0.24 & 0.085 & $-0.05^{*}$ & 0.047 \\
\hline Monthly income & 0.43 & 0.109 & 0.18 & 0.087 & 0.39 & 0.064 & 0.19 & 0.105 \\
\hline Possessed driver's license & $-0.13^{*}$ & 0.041 & -0.11 & 0.065 & -0.27 & 0.129 & $-0.12^{*}$ & 0.037 \\
\hline Past behavior & $0.47^{*}$ & 0.016 & $0.29^{*}$ & 0.041 & $0.35^{*}$ & 0.015 & $0.23^{*}$ & 0.027 \\
\hline
\end{tabular}

Goodness-of-fit statistics: CFI $=0.909$; GFI $=0.923$; NFI $=0.916$; $\mathrm{RMSEA}=0.068 .{ }^{*} P<0.05$.

months were more likely to perform riding violations. "Age $(18-30)$ " and "past behavior" had significant effects on all three belief composites, while "college diploma" and "possessed a driver's license" had significant effects on behavioral belief. Thus, hypothesis 3 was supported.

\section{Discussion}

The aim of this study was to predict and explain e-bike couriers' self-reported traffic violation behavior, to elicit key beliefs, and to develop an intervention strategy for altering the violation behavior of such couriers. The results of this study indicate that the TPB model well explains e-bike couriers' traffic violation behavior intentions and behavior. Attitudes, descriptive norms, and perceived behavioral control explained $55.7 \%$ of the variance in intentions to engage in traffic violation behavior. Perceived behavioral control and behavioral intention together accounted for $28.5 \%$ of the variance in self-reported violation riding behavior. This study provides empirical support for using the TPB model to explain traffic violation behavior in vulnerable road users, such as e-bike couriers.

Among the four TPB constructs, attitude, descriptive norms, and perceived behavioral control had significant impacts on the intention to perform traffic violation behavior. However, injunctive norms were not significant in the model. This outcome was consistent with many driving behavior studies, in which subjective norms normally had no significant impact on behavioral intention [29-31]. Interestingly, descriptive norms were a significant predictor of behavioral intentions, indicating that descriptive norms are more salient than subjective norms for this situation.

The strong impact of attitude on intentions in this study is especially noteworthy. This finding highlights the importance of altering the attitude of e-bike couriers to perform traffic violation behavior. Examination of the specific control beliefs that impacted attitude among the sample revealed three factors of particular importance: save time, more convenient, and the more the deliveries, the higher the earnings. These findings provide useful information for interventions designed to prevent traffic violation behavior by means of altering people's attitude. For example, it may be possible to prevent couriers racing against time by strengthening safety management at express delivery enterprises and by ensuring that delivery times are reasonable.
Implementing and enforcing extension of delivery times in accordance with the characteristics of the different delivery route will be very challenging but might be effective if used in conjunction with other measures to improve e-bike couriers' safety.

Five control beliefs were found to have significant effects on perceived behavior control toward intention and behavior: received an urgent request from a customer, heavy goods scooter, familiarity with the local roads, will be fined, and the traffic police officers on duty. Together with the finding that perceived control was already quite positive, this suggests that interventions targeted at perceived behavioral control are also to be effective. Thus, we could prevent couriers from performing traffic violation behavior through educational programs, traffic law enforcement, and encouraging the use of standard delivery e-bikes (e-bikes designed to comply with a maximum speed of $20 \mathrm{~km} / \mathrm{h}$, a maximum weight of $45 \mathrm{~kg}$, and a maximum power of $240 \mathrm{~W}$ ) [29].

"Workmates behavior" and "Other road users' behavior" were found to have significant effects on descriptive norms. By observing that workmates and other road users violate traffic laws, an e-bike courier would imitate the behavior. It is worth mentioning that descriptive norm is not always a significant predictor to the behavior intention, but it would have greater influence in predicting behavior that carries some form of risk [30], for example, e-bike couriers speeding against the traffic rules.

Several demographic variables had an effect on belief composites and behavior. Younger e-bike couriers were more likely to perform traffic violation behavior. This result was consistent with other studies where young people were more likely to violate traffic rules [32,33]. Having a college degree and possessing a driver's license had negative effects on traffic violation behavior by e-bike couriers. This outcome was consistent with an earlier study on e-bike users who run red lights [19]. An e-bike courier involved in traffic violation behavior during the previous 3 months was more likely to perform traffic violation behavior. Our study also provides evidence that past behavior should be considered when designing interventions on traffic violation behavior. In addition, different demographic variables also had significant effects on behavioral beliefs, descriptive beliefs, and control beliefs. These findings can be used to target populations in which an intervention strategy might be most effective. 
Generally, this study provides useful information for developing effective policies to improve e-bike courier's safety. Two potential limitations of the study can be investigated further. One is that the study relies on self-reported traffic violation behavior, and thus the results may be affected by the possibility that the participants have a psychological bias regarding negative behavior. The other is that the TPB model predicted only $28.5 \%$ of e-bike traffic violation behavior. This outcome may have occurred because several key extended TPB constructs were ignored. In further studies, the questionnaire design could be improved to better capture the latent psychological factors. Additionally, it would be meaningful to improve the predictive ability of the TPB model by extending the standard TPB model with an interaction term between the basic TPB constructs and personality traits.

\section{Data Availability}

The data used to support the findings of the manuscript are available from the corresponding author (Qian Cheng; 13851522967@139.com) upon request.

\section{Conflicts of Interest}

The authors declare that they have no conflicts of interest.

\section{Acknowledgments}

This study was funded by the Key Project of Philosophy and Social Science Research in Colleges and Universities in Jiangsu Province (Grant no. 2020SJZDA136).

\section{References}

[1] W. Jing, "Shanghai annual traffic accident report for e-bike couriers," 2017, http://www.shanghai.com.cn.

[2] Z. Wang, "A delivery man had three accidents in one month," 2018, http://www.sohu.com.

[3] L. Liao, "A delivery boy was involved an average of 18 traffic accidents in one day," 2018, http://www.yangtse.com.

[4] Nanjing Police Department, Annual Traffic Safety Report 2017 (ATSR, 2017), Nanjing Police Department, Nanjing, China, 2018.

[5] J. Cestac, F. Paran, and P. Delhomme, "Young drivers' sensation seeking, subjective norms, and perceived behavioral control and their roles in predicting speeding intention: how risk-taking motivations evolve with gender and driving experience," Safety Science, vol. 49, no. 3, pp. 424-432, 2011.

[6] K. Chorlton, M. Conner, and S. Jamson, "Identifying the psychological determinants of risky riding: an application of an extended theory of planned behaviour," Accident Analysis \& Prevention, vol. 49, pp. 142-153, 2012.

[7] M. Cristea and P. Delhomme, "The effects of co-presence on risk perception and intention to engage in risky behaviors," Journal of Safety Research, vol. 56, pp. 97-103, 2016.

[8] Y. Guo, A. Osama, and T. Sayed, "A cross-comparison of different techniques for modeling macro-level cyclist crashes," Accident Analysis \& Prevention, vol. 113, pp. 38-46, 2018.

[9] B. Dohnke, E. Weiss-Gerlach, and C. D. Spies, "Social influences on the motivation to quit smoking: main and moderating effects of social norms," Addictive Behaviors, vol. 36, no. 4, pp. 286-293, 2011.

[10] E. M. Duncan, K. E. Forbes-Mckay, and S. E. Henderson, "Alcohol use during pregnancy: an application of the theory of planned Behavior1," Journal of Applied Social Psychology, vol. 42, no. 8, pp. 1887-1903, 2012.

[11] I. Ajzen, "The theory of planned behavior," Organizational Behavior and Human Decision Processes, vol. 50, no. 2, pp. 179-211, 1991.

[12] I. Ajzen, "The theory of planned behavior," in Handbook of Theories of Social Psychology, P. A. M Lange, A. W. Kruglanski, and E. T. Higgins, Eds., vol. 1, pp. 438-459, Sage, London, UK, 2012.

[13] M. Fishbein and I. Ajzen, Predicting and Changing Behavior: The Reasoned Action Approach, Psychology Press, New York, NY, USA, 2010.

[14] R. Zhou, P.-L. P. Rau, W. Zhang, and D. Zhuang, "Mobile phone use while driving: predicting drivers' answering intentions and compensatory decisions," Safety Science, vol. 50, no. 1, pp. 138-149, 2012.

[15] B. K. Barton, S. M. Kologi, and A. Siron, "Distracted pedestrians in crosswalks: an application of the theory of planned behavior," Transportation Research Part F: Traffic Psychology and Behaviour, vol. 37, pp. 129-137, 2016.

[16] K. Jiang, F. Ling, Z. Feng, K. Wang, and C. Shao, "Why do drivers continue driving while fatigued? An application of the theory of planned behaviour," Transportation Research Part A: Policy and Practice, vol. 98, pp. 141-149, 2017.

[17] I. S. Moan and J. Rise, "Predicting intentions not to "drink and drive" using an extended version of the theory of planned behaviour," Accident Analysis \& Prevention, vol. 43, no. 4, pp. 1378-1384, 2011.

[18] H. Zhou, S. B. Romero, and X. Qin, "An extension of the theory of planned behavior to predict pedestrians' violating crossing behavior using structural equation modeling," Accident Analysis \& Prevention, vol. 95, pp. 417-424, 2016.

[19] H. Yang, X. Liu, F. Su, C. Cherry, Y. Liu, and Y. Li, "Predicting e-bike users' intention to run the red light: an application and extension of the theory of planned behavior," Transportation Research Part F: Traffic Psychology and Behaviour, vol. 58, pp. 282-291, 2018.

[20] K. Jiang, F. Ling, Z. Feng, K. Wang, and L. Guo, "Psychological predictors of mobile phone use while crossing the street among college students: an application of the theory of planned behavior," Traffic Injury Prevention, vol. 18, no. 2, pp. 118-123, 2017.

[21] I. Ajzen, Attitudes, Personality, and Behavior, Open University Press, London, UK, 2nd edition, 2005.

[22] F. G. Castro, J. G. Kellison, S. J. Boyd, and A. Kopak, "A methodology for conducting integrative mixed methods research and data analyses," Journal of Mixed Methods Research, vol. 4, no. 4, pp. 342-360, 2010.

[23] B. Kidwell and R. D. Jewell, "An examination of perceived behavioral control: internal and external influences on intention," Psychology and Marketing, vol. 20, no. 7, pp. 625-642, 2003.

[24] J. F. Hair, B. Black, B. Babin, and R. E. Anderson, Multivariate Data Analysis: A Global Perspective, Pearson Education Inc, Hoboken, NJ, USA, 2010.

[25] Y. Guo, T. Sayed, and M. H. Zaki, "Exploring evasive actionbased indicators for PTW conflicts in shared traffic facility environments," Journal of Transportation Engineering, Part A: Systems, vol. 144, no. 11, Article ID 04018065, 2018. 
[26] B. M. Byrne, Structural Equation Modeling with AMOS, Taylor and Francis Group, New York, NY, USA, 2010.

[27] R. B. Kline, Principles and Practices of Structural Equation Modeling, Guilford Press, New York, NY, USA, 4th edition, 2015.

[28] Y. Guo, Z. Li, Y. Wu, and C. Xu, "Evaluating factors affecting electric bike users' registration of license plate in China using Bayesian approach," Transportation Research Part F: Traffic Psychology and Behaviour, vol. 59, pp. 212-221, 2018.

[29] J. Cestac, F. Paran, and P. Delhomme, "Drive as I say, not as I drive: influence of injunctive and descriptive norms on speeding intentions among young drivers," Transportation Research Part F: Traffic Psychology and Behaviour, vol. 23, pp. 44-56, 2014.

[30] A. Rivis and P. Sheeran, "Descriptive norms as an additional predictor in the theory of planned behaviour: a meta-analysis," Current Psychology, vol. 22, no. 3, pp. 218-233, 2003.

[31] M. Conner, R. Lawton, D. Parker, K Chorlton, A. S Manstead, and S Stradling, "Application of the theory of planned behaviour to the prediction of objectively assessed breaking of posted speed limits," British Journal of Psychology, vol. 98, pp. 429-453, 2007.

[32] C. Holland and R. Hill, "The effect of age, gender and driver status on pedestrians' intentions to cross the road in risky situations," Accident Analysis \& Prevention, vol. 39, no. 2, pp. 224-237, 2007.

[33] R. Zhou, W. J. Horrey, and R. Yu, "The effect of conformity tendency on pedestrians' road-crossing intentions in China: an application of the theory of planned behavior," Accident Analysis \& Prevention, vol. 41, no. 3, pp. 491-497, 2009. 